\title{
Effect of six-week intervention program on postural stability measures and muscle coactivation in senior-aged women
}

This article was published in the following Dove Press journal:

Clinical Interventions in Aging

\section{Zbigniew Borysiuk \\ Mariusz Konieczny \\ Krzysztof Kręcisz \\ Paweł Pakosz \\ Bożena Królikowska}

Faculty of Physical Education and Physiotherapy, Opole University of Technology, Opole, Poland
Correspondence: Mariusz Konieczny Faculty of Physical Education and Physiotherapy, Opole University of Technology, Prószkowska 76/9A, 45-758 Opole, Poland

Tel +48 774498247

Email m.konieczny@po.opole.pl
Objective: The objective involved the analysis of the efficiency of the Program of Movement Recreation of Elderly People (PMREP) exercise program expressed in terms of the stabilography measures and coactivation of muscles in women in the age group of 60-70 years. The assumption that was assumed stems from theoretical implications that the adequate postural stability is manifested in the decrease of the body sways measured by means of a force plate.

Materials and methods: The study involved a group of 60 females, all members of the active seniors' association. The subjects were in the age range from 60 to 70 years. The subjects were divided into 2 groups of equal size: control and experimental. Subjects in both groups participated in the rehabilitation exercises: experimental ( $n=16$, PMREP - twice a week/60 minutes), control ( $\mathrm{n}=27$, PMREP - only once a week/60 minutes).

Results: The study demonstrated that the completion of a 6-week PMREP program resulted in a decrease in the variability and velocity as well as indicators representing center of pressure displacement measured in the feet for the exercises performed with closed eyes with subjects standing on a high foam pad located on a force plate $(P=0.001)$. No significant changes in coactivation of the calf muscles were recorded in the subjects.

Conclusion: The study concludes that a PMREP rehabilitation plan with an adequate program and frequency leads to an improvement of the vestibular system coupled with proprioception understood as an integrated process of sensor activation in the body. However, in regard to the coactivation of the muscles involved in maintaining postural stability, no significant differences have been observed.

Keywords: stabilography, EMG signal, sensory integration, aging

\section{Introduction}

There is high likelihood that people $>60$ years of age will account for about $25 \%$ of the population in the developed countries in the years to come. ${ }^{1}$ This is due to demographic reasons, improvement of the quality of life and its longer duration resulting from progress in medicine, and positive trends in pro-health behaviors. Aging itself is a multifaceted process that is often described in the literature in terms of the decline in physical activity that accompanies the process, resulting in deficiencies in the circulatory and respiratory capacity, ${ }^{2-4}$ neurological limitations, and the progressive process of deterioration in terms of the ability to maintain postural control performance.

This phenomenon reduces motor activity and contributes to an increase in the number of falls in the elderly persons. Injuries resulting from the deterioration of postural control accompanying the aging process are considered a considerable social and economic problem, as their occurrence is often associated with the need to 
perform long-term rehabilitation. Falls often have immediate consequences not only in the form of bone fractures or head injuries, but also long-term effects, such as feeling of anxiety, insecurity, fear of loss of independence, or disability in the elderly. ${ }^{5}$ In turn, it has been repeatedly demonstrated that improving strength and balance training reduces the risk of falling by as much as $50 \%$ in the elderly. ${ }^{6,7}$ Hence, the important role of this issue has encouraged the authors to conduct research into the activity of older people. The specific phenomenon was named "frailty syndrome" in the senior group. Currently, more and more studies and various types of training programs are readily available for seniors. However, normalization and unification of the therapy program form a considerable challenge due to the differences in the level of seniors' activity, old age definitions, and concomitant diseases associated with old age. ${ }^{1,8,9}$

This paper focuses on looking for factors that strengthen the functions of the vestibular system in association with the proprioception apparatus responsible for postural balance control. ${ }^{10-12}$ Because of the important role that balance disorders play in the pathogenesis of falls, it is crucial to develop new effective methods aimed at improving balance control. The objective involved analysis of the efficiency of the Program of Movement Recreation of Elderly People (PMREP) exercise program, the scope of which was modified by supplementing the program with exercises designed to develop sensomotor abilities. Their aim was to stimulate the function of proprioceptive system, also known to affect the improvement and efficiency of the vestibular system.

The realized program involved health-promotion exercises that were combined with elements of balance training. This type of exercise can be of assistance to the elderly subjects, as it provides them with the necessary skills and knowledge that can be used to perform simple exercises at home to enhance health and balance training. If such exercises are performed by the subjects at home, there is a chance that they can improve the quality of life. The study also involved information and education program aimed at raising the awareness with regard to regular physical activity as part of the everyday life of an elderly person. The success of the program is demonstrated by the fact that $90 \%$ of the participants decided to perform the health-promoting activities (and participate in organized training programs).

The main goal of the research experiment involved the evaluation of the effectiveness of the modified PMREP program on stabilography parameters and muscle coactivation in elderly women.

Low values of sway indices derived from the center of pressure (COP) displacements measured by force plate are indicators of better performance. In addition, low signal emitted from muscle activation in the lower leg demonstrates the rational use of energy related to postural balance. It was anticipated that a 6-week rehabilitation program exercises could result in a decrease in the indicators representing COP, including variation and velocity of the COP displacement acting on the plantar surface of the feet. The deviation of the coactivation coefficient of the muscles in the calf was also an anticipated outcome of the exercise.

\section{Materials and methods Participants}

The study involved a group of 60 women aged 60-70 years, members of seniors' association, whose activity was based in the province town of Opole. The participation in the program was preceded by a prior recruitment carried out in the environment of Opole seniors (promotional and educational campaign was organized for this purpose), based on an assumption that the subjects who do not undertake regular physical activity should be selected to participate in the study. Another prerequisite for participation was associated with lack of health contraindications and voluntary participation of the participants.

The subjects were divided into 2 identical groups of equal size: control $(\mathrm{CON})$ and experimental (EXP). For various reasons, 27 subjects in the CON group and 16 subjects in the EXP completed the experiment. The anthropometric data are summarized in Table 1. Throughout the course of the program, the number of participants decreased due to health-related and personal reasons. The duration of the program, frequency, and number of classes were established while taking into account the will of the participants and what is feasible following the stage when activities applied to promote the program were implemented. The major principles of health training had also been taken into account. Participants in the study were asked not to participate in other forms of recreational physical activity for the duration of the program.

Table I Characteristics of examined group

\begin{tabular}{|c|c|c|c|c|}
\hline & Number & Age, years & Height, cm & Weight, kg \\
\hline & $\begin{array}{l}\text { of partici- } \\
\text { pants }\end{array}$ & $\overline{(\text { mean } \pm S D)}$ & $\overline{(\text { mean } \pm S D)}$ & $($ mean $\pm S D)$ \\
\hline $\begin{array}{l}\text { Control } \\
\text { group (CON) }\end{array}$ & 27 & $69.5 \pm 4.6$ & $161.9 \pm 7.2$ & $74.2 \pm I I .4$ \\
\hline $\begin{array}{l}\text { Experimental } \\
\text { group (EXP) }\end{array}$ & 16 & $66.4 \pm 5.9$ & $159.0 \pm 6.1$ & $70.2 \pm 13.9$ \\
\hline
\end{tabular}




\section{Inclusion criteria}

The following inclusion criteria were adopted during the study: ability to comprehend commands and actively participate in the program (based on mini mental state examination $<23$ points); capability to participate actively in the physical program projected within the PMREP (ie, ability to move without constraints); lack of lower limb injury and medical contraindications to participate in moderate physical exercise, and an agreement to take over the role of test subject. The criteria adopted as the basis for the potential rejection of an application included: aphasia, significant loss of sight or hearing, which makes it impossible to assess cognitive functions, as well as voluntary resignation from participation in the study.

Subjects in both groups participated in the rehabilitation exercises, with the only difference being that the EXP group took part in the exercises twice weekly for 60 minutes, whereas the CON one only once per week with the same duration. Every time, the exercise program involved a similar schedule comprising a warm-up, core part, and a final part focusing on muscular relaxation and relieve of tension. Classes were organized in a room suitably adapted to this type of exercise, equipped with mirrors, handrails, ladders, and other suitable equipment. The modified program also included equivalent classes on stable and unstable surface as described by data in Table 2. The participants of the study signed the written informed consent. The goal of the study was approved by the Bioethics Committee of the Chamber of Physicians (Resolution No. 237 of 13 December 2016) in

Table 2 Details of balance exercise program

\section{Program}

I. Standing with legs slightly apart, and slightly bent knees. The center of pressure is transferred forward and back (toes to heels).

2. Standing with legs slightly apart with both arms extended to the side, alternating leg bends at the hip and knee joints up to $90^{\circ}$.

3. Standing with legs slightly apart and supported by the ladder; alternately, knees are lifted to reach to the bent elbow of the opposite arm.

4. Standing with legs slightly apart on a $10 \mathrm{~cm}$ foam pad, legs are alternately bent at the hip and knee joints up to $90^{\circ}$ - with open eyes and then with closed eyes.

5. Standing with legs slightly apart on a $10 \mathrm{~cm}$ foam pad, legs are alternately bent at the hip and knee joints up to $90^{\circ}$ (for 30 seconds) - with open eyes and then with closed eyes.

6. Exercise in pairs. A slight nudge is given to person holding the posture of an inverted pendulum. The task of the subject is to return to a vertical position.

7. March forward with a $360^{\circ}$ rotation in the indicated direction in response to a signal of the coach, the march is continued after the turn.

8. March in reverse directions (forward and backward).

9. March along a variable ground (mattress and bench). accordance with the guidelines described in the Declaration of Helsinki involving humans.

The following methods and materials were described in our previous work. ${ }^{10}$ Briefly, the COP was recorded with the force platform and the bioelectric activity of the right and left tibialis anterior and soleus muscles was registered and processed by Noraxon sensors with the procedure followed the surface EMG for non-invasive assessment of muscles methodology. ${ }^{7,8}$

The subjects in both groups were measured prior to and after the exercise program. The maximum voluntary contraction (MVC) of the examined muscles was performed over a 5 second voluntary contraction and was used as a reference value. The outcome variables were measured in the following 4 trials: 1) quiet stance with eyes open (EO), 2) quiet stance with eyes closed (EC), 3) quiet stance with EO on a foam pad placed on a force plate, and 4) quiet stance with EC on a foam pad placed on a force plate. The instantaneous COP of foot was calculated from the components of forces of the registered plate response were separately analyzed in then medio-lateral (ML) and anterior-posterior (AP) planes. Each successive measurement using the force plate lasted for 30 seconds, and throughout this time, the activity of the selected muscles of the lower limbs was monitored by means the surface EMG (sEMG) system. The subjects maintained the following foot position: $14^{\circ}$ angle between the feet and $17 \mathrm{~cm}$ distance between the heels. ${ }^{13}$ The registration of COP was performed by a force plate (type: 9286AA; Kistler Group, Winterthur, Switzerland), with a sampling frequency of $100 \mathrm{~Hz}$, and the duration of the test equal to 30 seconds. The electromyographic study applied 16 channel sEMG signals (type DTS EMG; Noraxon, Scottsdale, AZ, USA) recorded with the 16 bit resolution and a sampling frequency of $1,500 \mathrm{~Hz}$.

The COP of foot was separately analyzed in ML and AP planes. The linear parameters of COP signal comprised SD of the time series (in $\mathrm{mm}$ ) and mean velocity ( $\mathrm{MV}$ in $\mathrm{mm} / \mathrm{s}$ ). The lower values of these parameters indicate a more effective postural control.

The sEMG signals were smoothened by estimation of the root mean square that was derived in the time window of $300 \mathrm{~ms}$. The reference value of the MVC was calculated in a time window equal to $1,000 \mathrm{~ms}$ for which the mean value of the sEMG signal was the highest.

The coactivation index (CI) of the muscles was calculated using the Falconer and Winter method. ${ }^{12}$ The CI was computed separately for the left and right legs.

\section{Statistical methods}

The indices of the COP and sEMG signals were subjected to the Shapiro-Wilk normality test. The distributions of the 
analyzed variables were not deviating from normality. Thus, the parameters of signals were subjected to ANOVA with 0.05 significant threshold. The factors included: time (before, after), sight (closed vs open eyes), surface (floor, matt), plane for the case of analysis of variability, MV (AP and ML), and side (left vs right) for the case of the CI.

\section{Results}

The descriptive statistics of the measured indices for all tasks performed by the subjects are summarized in Table 3 .

The study did not reveal the effect of the intervention program on inter-group performance. Vision, surface, and plane were found to affect the SD and MV COP parameters $(P<0.001)$. For the CI, only vision and surface have shown main effect $(P<0.001)$. The intervention time affects the results only in the form of a few interactions (Table 4).

Table 3 Mean values and SDs of COP and sEMG parameters recorded in the particular trials

\begin{tabular}{|c|c|c|c|c|c|c|c|c|}
\hline \multirow[t]{3}{*}{ Parameters } & \multicolumn{4}{|l|}{ CON } & \multicolumn{4}{|l|}{ EXP } \\
\hline & \multicolumn{2}{|c|}{ Before } & \multicolumn{2}{|l|}{ After } & \multicolumn{2}{|c|}{ Before } & \multicolumn{2}{|l|}{ After } \\
\hline & Mean & SD & Mean & SD & Mean & SD & Mean & SD \\
\hline \multicolumn{9}{|l|}{$\overline{E O}$} \\
\hline VAR ML & 2.50 & 0.89 & 2.77 & 0.79 & 3.02 & 1.26 & 3.11 & 0.68 \\
\hline VAR AP & 3.87 & 1.09 & 4.76 & 1.45 & 5.23 & 1.51 & 5.60 & 1.69 \\
\hline MV ML & 5.19 & 1.21 & 6.12 & 1.63 & 6.18 & 2.39 & 6.95 & 2.09 \\
\hline MV AP & 10.80 & 5.29 & 11.82 & 3.17 & 10.65 & 2.52 & 11.29 & 2.93 \\
\hline $\mathrm{Cl} \mathrm{R}$ & 49.76 & 27.22 & 40.93 & 30.16 & 38.18 & 23.72 & 36.67 & 28.51 \\
\hline $\mathrm{Cl} \mathrm{L}$ & 50.56 & 29.46 & 42.84 & 28.58 & 37.43 & 24.22 & 41.71 & 28.68 \\
\hline \multicolumn{9}{|l|}{ EOF } \\
\hline VAR ML & 4.81 & 1.51 & 4.71 & 1.30 & 4.84 & 1.94 & 4.49 & 0.92 \\
\hline VAR AP & 6.88 & 2.20 & 6.90 & 2.24 & 7.48 & 3.84 & 7.49 & 2.40 \\
\hline MV ML & 11.48 & 3.70 & $|0.7|$ & 3.28 & 11.36 & 3.43 & $|0.7|$ & 2.34 \\
\hline MV AP & 15.07 & 4.37 & 15.67 & 4.57 & 14.77 & 2.64 & 15.38 & 3.55 \\
\hline $\mathrm{Cl} \mathrm{R}$ & 30.97 & 19.99 & 23.75 & 23.95 & 27.27 & 21.70 & 21.74 & 25.89 \\
\hline $\mathrm{Cl} \mathrm{L}$ & 32.41 & 22.41 & 29.63 & 22.21 & 28.88 & 22.56 & 20.23 & 18.09 \\
\hline \multicolumn{9}{|l|}{ EC } \\
\hline VAR ML & 2.52 & 0.74 & 2.50 & 0.65 & 2.73 & 0.89 & 3.19 & 1.30 \\
\hline VAR AP & 4.54 & 1.60 & 4.82 & 1.59 & 4.91 & 0.93 & 5.32 & 1.11 \\
\hline MV ML & 6.19 & 2.18 & 6.32 & 1.70 & 6.58 & 2.37 & 7.80 & 2.56 \\
\hline MV AP & 13.93 & 5.82 & 14.00 & 4.88 & 15.62 & 11.18 & 14.16 & 5.64 \\
\hline $\mathrm{Cl} \mathrm{R}$ & 50.94 & 27.77 & 38.92 & 27.97 & 43.24 & 26.58 & 35.80 & 30.62 \\
\hline $\mathrm{Cl} \mathrm{L}$ & 48.15 & 29.59 & 48.67 & 21.96 & 43.20 & 28.63 & 42.81 & 31.20 \\
\hline \multicolumn{9}{|l|}{ ECF } \\
\hline VAR ML & 5.99 & 2.02 & 6.08 & 2.15 & 6.96 & 2.14 & 5.80 & 2.10 \\
\hline VAR AP & 8.87 & 3.53 & 8.87 & 2.74 & 9.15 & 2.23 & 7.57 & 1.68 \\
\hline MV ML & 16.58 & 5.87 & 16.61 & 6.82 & 20.89 & 8.86 & 15.09 & 6.98 \\
\hline MV AP & 25.29 & 9.77 & 24.67 & 9.48 & 30.05 & $|6.7|$ & 21.50 & 7.05 \\
\hline $\mathrm{Cl} \mathrm{R}$ & 47.28 & 23.73 & 41.64 & 25.42 & 40.71 & 22.36 & 32.11 & 23.80 \\
\hline $\mathrm{CI} \mathrm{L}$ & 50.87 & 26.58 & 42.37 & 21.75 & 46.03 & 27.28 & 33.71 & 24.67 \\
\hline
\end{tabular}

Abbreviations: $\mathrm{Cl}$ R, coactivation index of right hand; $\mathrm{Cl}$, coactivation index of left hand; CON, control; COP, center of pressure; EO, eyes open; EOF, eyes open on a foam; EC, eyes closed; ECF, eyes closed on a foam; EXP, experimental; $M$, mean; MV $\mathrm{ML}$, mean velocity in mediolateral; MV AP, mean velocity in anterior-posterior planes; sEMG, surface EMG; VAR ML, standard deviation of the time series mediolateral; VAR AP, standard deviation of the time series anterior-posterior planes.
Both in regard to the stabilography parameters and EMG, the study did not reveal the effect of the duration of the test. This duration affects the results only in the form of a few interactions marked in the table.

The chart below (Figure 1) illustrates the interaction TIME $\times$ GROUP for the MV demonstrating the significant improvements in the EXP group.

The chart (Figure 2) illustrates the interaction TIMEX VISION $\times$ GROUP for the MV demonstrating the significant improvements in the EXP group in subjects performing tasks with closed eyes.

The chart Figure 3 illustrates the interaction TIMEX SURFACE $\times$ GROUP for the MV demonstrating the significant improvements in the EXP group in subjects performing tasks on a high foam pad.

\section{Discussion}

The study that was conducted confirms the hypothesis regarding the positive effect of the balance training associated with functional task, and health-related quality of life in middle-aged and older adults. ${ }^{14}$ The active lifestyle and exercise applied during the 6-week program demonstrate a statistically significant interaction, in which a decrease in the MV of COP displacement was noted for subjects' EC for exercise performed on a pad in the EXP group.

When we apply the basics defined in the theory of the control and regulation of motor activity in humans, we learn that the motor system is based on reflexes occurring at the level of the spinal cord and along afferent and efferent pathways, and involve a small degree of the conscience. This type of motor activity involves the maintenance of the postural balance and walking activity. This type of motor activity concerns the maintenance of postural stability and ability to walking and depends on the cooperation between the antagonist muscles and the patterns are known to vary in the subjects depending on their age. ${ }^{15,16}$ The aforementioned processes are attributable to the motor habits in the form of automatism and voluntary movement, subjected to the control of the central nervous system, in particular in the motor cortex and cerebellum.

The commands are carried from the decision centers initiate motor units (MU) through motoneurons, and result in the activation of skeletal muscles. The number of MU activated gives the bioelectric muscle tension that can be expressed by means of the value of the sEMG signal. ${ }^{17}$

The assessment of the balance control performed with the use of a platform posturography shows the oscillations of the subject bodies measured in terms of the COP in the AP and ML planes. The correct balance control in healthy people is achieved as a result of adequate processing of the 
Table 4 The ANOVA results for variability, $\mathrm{MV}$, and $\mathrm{Cl}$

\begin{tabular}{|c|c|c|c|c|c|c|c|}
\hline \multirow[t]{2}{*}{ Effects } & \multicolumn{2}{|l|}{ SD } & \multicolumn{2}{|l|}{ MV } & & \multicolumn{2}{|l|}{ Cl } \\
\hline & $\mathbf{F}$ & P-value & $\mathbf{F}$ & $P$-value & & $\mathbf{F}$ & P-value \\
\hline I) GROUP & 1.70 & 0.199 & 0.24 & 0.628 & I) GROUP & 1.76 & 0.193 \\
\hline 2) TIME & 0.01 & 0.912 & 3.18 & 0.082 & 2) TIME & 3.29 & 0.077 \\
\hline TIME*GROUP & 1.27 & 0.266 & 4.85 & 0.033 & TIME*GROUP & 0.00 & 0.949 \\
\hline 3) VISION & 17.06 & 0.000 & 57.20 & 0.000 & 3) VISION & 26.95 & 0.000 \\
\hline VISION*GROUP & 0.90 & 0.349 & 0.51 & 0.479 & VISION*GROUP & 1.42 & 0.240 \\
\hline 4) SURFACE & 204.36 & 0.000 & 228.17 & 0.000 & 4) SURFACE & 17.46 & 0.000 \\
\hline SURFACE*GROUP & 1.70 & 0.199 & 0.02 & 0.884 & SURFACE*GROUP & 1.09 & 0.302 \\
\hline 5) PLANE & 300.54 & 0.000 & 106.64 & 0.000 & 5) SIDE & 1.09 & 0.303 \\
\hline PLANE*GROUP & 0.21 & 0.647 & 0.18 & 0.670 & SIDE*GROUP & 0.48 & 0.491 \\
\hline TIME*VISION & $\mathrm{I} .82$ & 0.185 & 10.66 & 0.002 & TIME*VISION & 0.09 & 0.769 \\
\hline TIME*VISION*GROUP & 0.41 & 0.526 & 6.13 & 0.018 & TIME*VISION*GROUP & $\mathrm{I} .44$ & 0.237 \\
\hline TIME*SURFACE & 4.77 & 0.035 & 12.85 & 0.001 & TIME*SURFACE & 0.03 & 0.853 \\
\hline TIME*SURFACE*GROUP & 1.28 & 0.265 & 6.04 & 0.018 & TIME*SURFACE*GROUP & 1.25 & 0.271 \\
\hline VISION*SURFACE & 29.37 & 0.000 & 63.64 & 0.000 & VISION*SURFACE & 21.45 & 0.000 \\
\hline VISION*SURFACE*GROUP & 0.00 & 0.990 & 0.16 & 0.690 & VISION*SURFACE*GROUP & 0.02 & 0.884 \\
\hline TIME*PLANE & 0.55 & 0.461 & 1.03 & 0.316 & TIME*SIDE & 0.00 & 0.991 \\
\hline TIME*PLANE*GROUP & 0.28 & 0.602 & 2.10 & 0.155 & TIME*SIDE*GROUP & 0.08 & 0.779 \\
\hline VISION*PLANE & 0.03 & 0.853 & 19.89 & 0.000 & VISION*SIDE & 0.41 & 0.528 \\
\hline VISION*PLANE*GROUP & 6.68 & 0.013 & 0.09 & 0.768 & VISION*SIDE*GROUP & 0.02 & 0.885 \\
\hline SURFACE*PLANE & 2.58 & 0.116 & 0.19 & 0.661 & SURFACE*SIDE & 0.02 & 0.875 \\
\hline SURFACE*PLANE*GROUP & 0.85 & 0.363 & 0.04 & 0.850 & SURFACE*SIDE*GROUP & 1.70 & 0.200 \\
\hline TIME*VISION*SURFACE & 0.93 & 0.339 & 7.92 & 0.007 & TIME*VISION*SURFACE & 0.99 & 0.325 \\
\hline TIME*VISION*SURFACE*GROUP & 4.62 & 0.038 & 12.08 & 0.001 & TIME*VISION*SURFACE*GROUP & 0.56 & 0.460 \\
\hline TIME*VISION*PLANE & $\mathrm{I} .25$ & 0.269 & 5.86 & 0.020 & TIME*VISION*SIDE & 0.01 & 0.920 \\
\hline TIME*VISION*PLANE*GROUP & 0.15 & 0.702 & 1.46 & 0.233 & TIME*VISION*SIDE*GROUP & 0.20 & 0.657 \\
\hline TIME*SURFACE*PLANE & 0.78 & 0.383 & 0.38 & 0.539 & TIME*SURFACE*SIDE & 0.00 & 0.950 \\
\hline TIME*SURFACE*PLANE*GROUP & 0.21 & 0.653 & 0.04 & 0.849 & TIME*SURFACE*SIDE*GROUP & 0.02 & 0.894 \\
\hline VISION*SURFACE*PLANE & 0.33 & 0.567 & 2.80 & 0.102 & VISION*SURFACE*SIDE & 0.30 & 0.586 \\
\hline VISION*SURFACE*PLANE*GROUP & 1.30 & 0.261 & 1.16 & 0.288 & VISION*SURFACE*SIDE*GROUP & 4.68 & 0.037 \\
\hline TIME*VISION*SURFACE*PLANE & 0.03 & 0.862 & 1.68 & 0.202 & TIME*VISION*SURFACE*SIDE & 0.48 & 0.492 \\
\hline $2 * 3 * 4 * 5 * 1$ & 0.09 & 0.768 & 0.03 & 0.869 & $2 * 3 * 4 * 5 * 1$ & 1.35 & 0.252 \\
\hline
\end{tabular}

Note: *shows the integration between the factors.

Abbreviations: $\mathrm{Cl}$, coactivation index; $\mathrm{MV}$, mean velocity.

sensory information originating from the vestibular system. ${ }^{18}$ The vestibular system when stimulated elicits responses that facilitate muscles to maintain the proper tension of the eyeballs and neck. In addition, it is responsible for correct postural

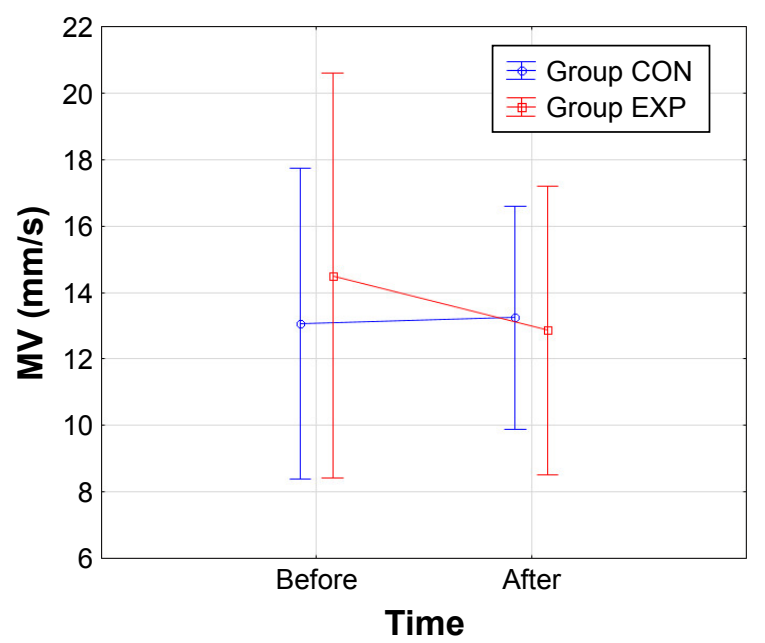

Figure I Significant interaction TIMEXGROUP for the MV.

Abbreviations: CON, control; EXP, experimental; MV, mean velocity. reflexes and is responsible for equivalent muscular reactions (displacement of the body COP). When the sense of sight was excluded from postural control in the conducted research, increased oscillations expressed in COP were recorded, which was also coupled with the increase in the indicators of COP displacement. These results are also confirmed by Asseman et $\mathrm{al}^{19}$ and Jones et al. ${ }^{20}$ The removal of vision is linked to the increase of COP mean velocity which suggest deterioration of postural control. This phenomenon can be prevented by applying appropriate exercises or therapy, which was also confirmed in a study by Mann et $\mathrm{al}^{21}$, Ruhe et $\mathrm{al}^{22}$ and Lihavainen et al. ${ }^{23}$ We can conclude that the adapted PMREP exercise program that differs from the standard motor activities performed in everyday life formed a set of new stimuli affecting the receptors in the vestibular system to achieve positive results.

A variety of different results can be found in the reports in this area. The studies in this subject ${ }^{16}$ revealed a correlation between coactivation of the examined muscles and the magnitude of oscillations at the level of 0.278 . This report involved subjects standing on a force plate with legs together 

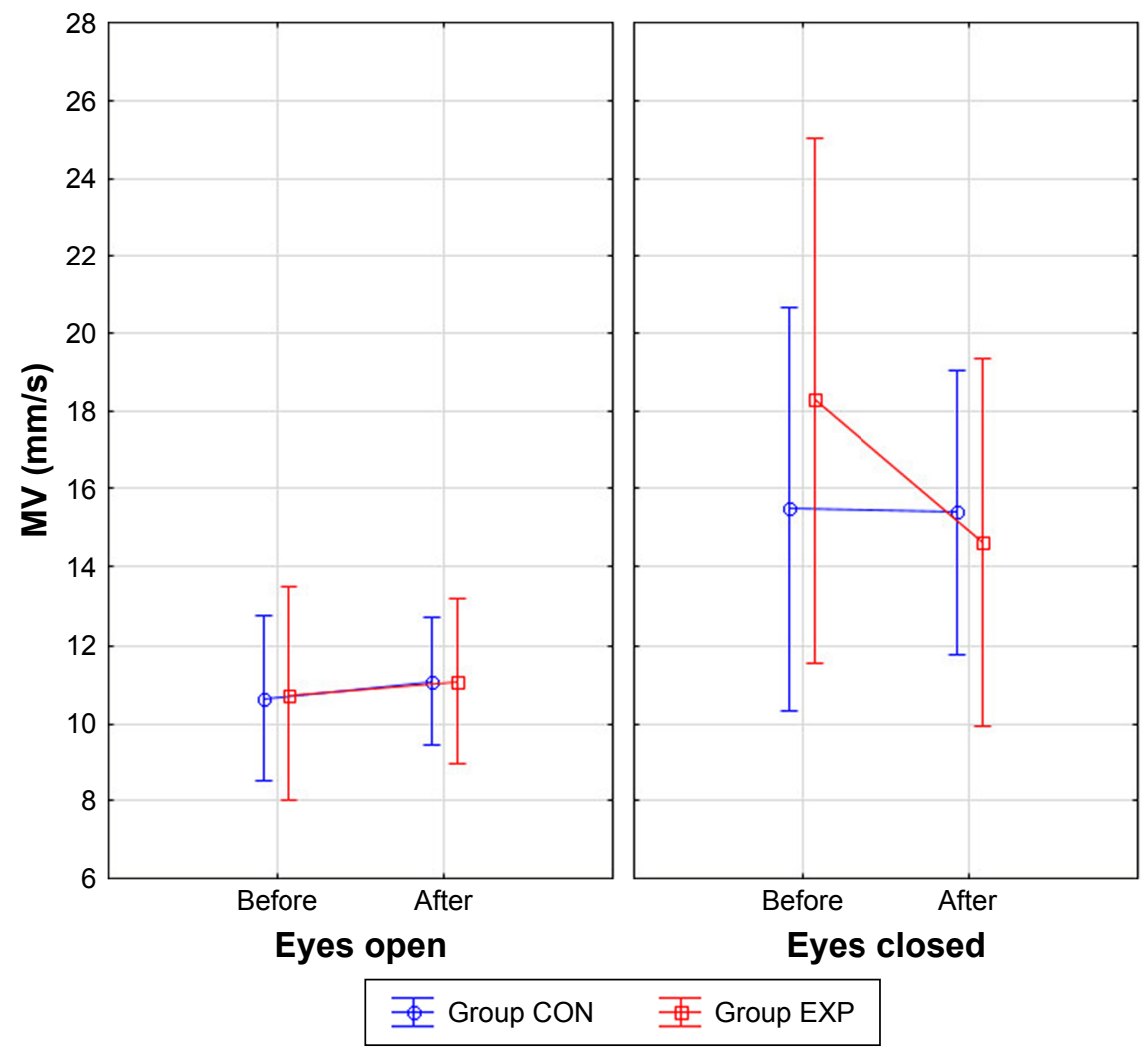

Figure 2 Significant interaction TIMEXVISION $\times$ GROUP for the MV. Abbreviation: MV, mean velocity.
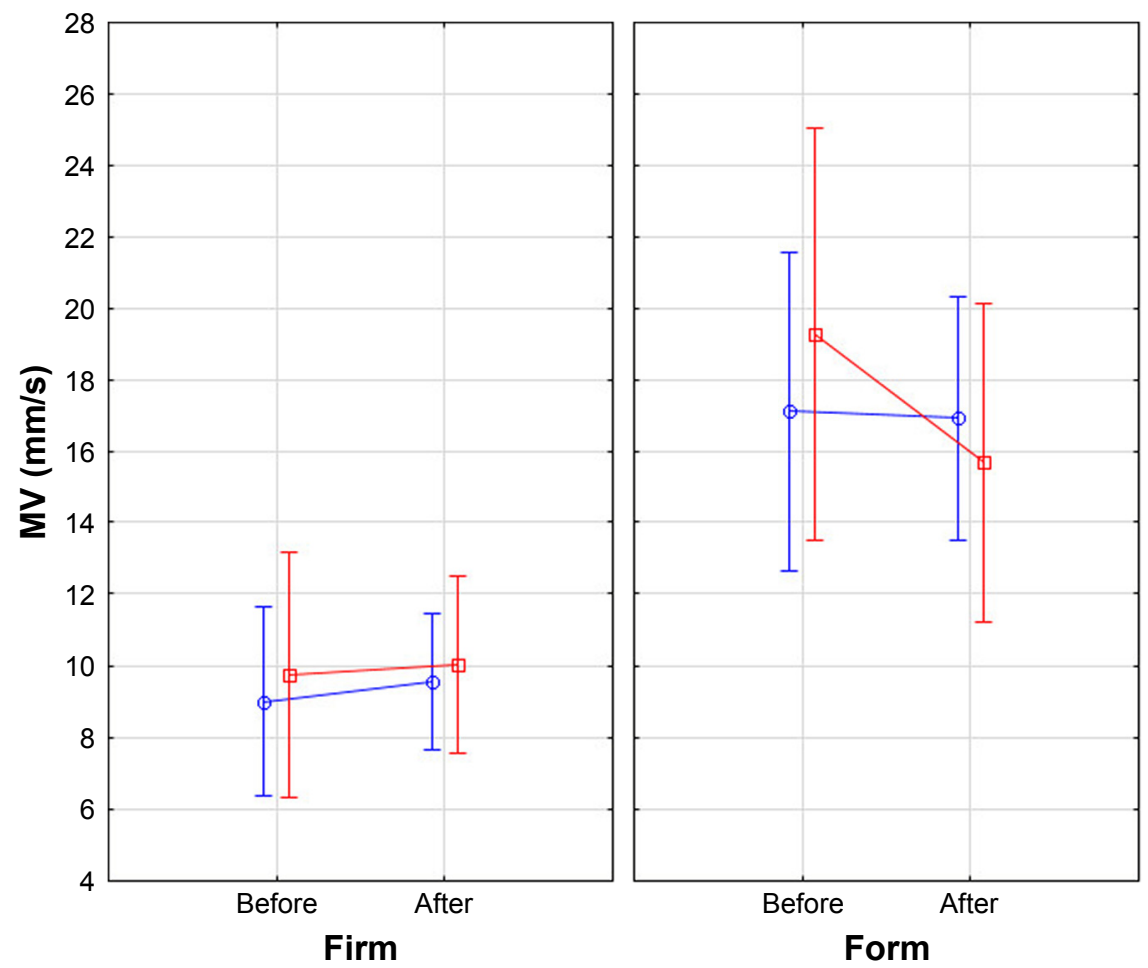

五 Group CON 更 Group EXP

Figure 3 Significant interaction TIMEXSURFACE $\times$ GROUP for the MV.

Abbreviations: CON, control; EXP, experimental; MV, mean velocity. 
for only 10 seconds where the coactivation was recorded on the basis of a 3-second sEMG signal. In research reported by Kouzaki et al, ${ }^{12}$ a correlation between MVC and COP variability was established in elderly subjects. The scope of these studies also involved a comparison of force variations between young and elderly subjects accompanying plantar flexion and their relation to the variability of the COP in the standing position. The elderly subjects demonstrated an increased activity of the antagonist muscles, which was found to relate to the greater fluctuations expressed by COP.

\section{Limitations of the study}

The present study did not involve men, and the reason was that too few senior-aged men were interested in participating in the study. In the future, senior-aged men should also be subjected to this type of analysis.

The testing should also be repeated by application of a more diverse and greater number of participants.

We can also note that the final outcomes were also considerably affected by the involvement on the part of the subjects, which was related to their different psychophysical condition throughout the particular exercises.

\section{Conclusion}

In summary, we can state that the positive outcomes of the experiment conducted on an unstable surface (high foam pad) during tests performed with the EC demonstrate that the control of the postural stability utilized neuromuscular mechanisms applying compensation that can be associated with the deep layers of the sensory system. The lack of a change of the coactivation of the muscles responsible for postural stability after the balance training imply that the rehabilitation program should be supplemented by moderate isometric strength training.

The implementation of the aforementioned program in the future, even including its potential modifications, seems to offer a feasible proposition of health-promoting activity among subjects $>60$ years of age. The program is also feasible in Polish conditions in various types of institutions whose activity is concerned with this social group.

\section{Disclosure}

The authors report no conflicts of interest in this work.

\section{References}

1. Zmijewski P, Mazurek K, Kozdron E, Szczypiorski P, Frysztak A. Effects of Organized Physical Activity on Selected Health Indices among Women Older than 55 Years. Sci World J. Vol. 2015, article ID 625032, 8 pages, 2015.

2. Sacha J, Sacha M, Sobon J, Borysiuk Z, Feusette P. Is It Time to Begin a Public Campaign Concerning Frailty and Pre-frailty? A Review Article. Front Physiol. 2017;8:484.
3. Drela N, Kozdron E, Szczypiorski P. Moderate exercise may attenuate some aspects of immunosenescence. BMC Geriatr. 2004;4(8):8.

4. Morey MC, Sloane R, Pieper CF, et al. Effect of physical activity guidelines on physical function in older adults. J Am Geriatr Soc. 2008; 56(10):1873-1878.

5. di Rosa M, Hausdorff JM, Stara V, et al. Concurrent validation of an index to estimate fall risk in community dwelling seniors through a wireless sensor insole system: A pilot study. Gait Posture. 2017;55:6-11.

6. Trombetti A, Hars M, Herrmann FR, Kressig RW, Ferrari S, Rizzoli R. Effect of music-based multitask training on gait, balance, and fall risk in elderly people: a randomized controlled trial. Arch Intern Med. 2011; 171(6):525-533.

7. Granacher U, Muehlbauer T, Zahner L, Gollhofer A, Kressig RW. Comparison of traditional and recent approaches in the promotion of balance and strength in older adults. Sports Med. 2011;41(5):377-400.

8. Cadore EL, Rodríguez-Mañas L, Sinclair A, Izquierdo M. Effects of different exercise interventions on risk of falls, gait ability, and balance in physically frail older adults: a systematic review. Rejuvenation Res. 2013; 16(2):105-114.

9. Puciato D, Borysiuk Z, Rozpara M. Quality of life and physical activity in an older working-age population. Clin Interv Aging. 2017;12:1627-1634.

10. Borysiuk Z, Konieczny M, Kręcisz K, Pakosz P. Application of sEMG and Posturography as Tools in the Analysis of Biosignals of Aging Process of Subjects in the Post-production Age. In: Biomedical Engineering and Neuroscience. BCI 2018. Advances in Intelligent Systems and Computing. Hunek W, Paszkiel S, editors. Vol. 720: Springer; 2018. Available from: https://link.springer.com/chapter/10.1007/978-3-31975025-5_3. Accessed August 11, 2018.

11. Mansfield A, Aqui A, Fraser JE, Rajachandrakumar R, Lakhani B, Patterson KK. Can augmented feedback facilitate learning a reactive balance task among older adults? Exp Brain Res. 2017;235(1):293-304.

12. Kouzaki M, Shinohara M. Steadiness in plantar flexor muscles and its relation to postural sway in young and elderly adults. Muscle Nerve. 2010;42(1):78-87.

13. Mcilroy WE, Maki BE. Preferred placement of the feet during quiet stance: development of a standardized foot placement for balance testing. Clin Biomech. 1997;12(1):66-70.

14. Nicholson VP, Mckean MR, Burkett BJ. Twelve weeks of Body Balance ${ }^{\circledR}$ training improved balance and functional task performance in middleaged and older adults. Clin Interv Aging. 2014;9:1895-1904.

15. Hortobágyi T, Solnik $S$, Gruber A, et al. Interaction between age and gait velocity in the amplitude and timing of antagonist muscle coactivation. Gait Posture. 2009;29(4):558-564.

16. Nagai K, Yamada M, Mori S, et al. Effect of the muscle coactivation during quiet standing on dynamic postural control in older adults. Arch Gerontol Geriatr. 2013;56(1):129-133.

17. Latash M. Neurophysiological Basics of Movement. 2nd ed. Human Kinetics, Urbana, IL; 2008.

18. Derlich M, Kręcisz K, Kuczyński M. Attention demand and postural control in children with hearing deficit. Res Dev Disabil. 2011;32(5):1808-1813.

19. Asseman F, Caron O, Crémieux J. Effects of the removal of vision on body sway during different postures in elite gymnasts. Int J Sports Med. 2005;26(2):116-119.

20. Jones SL, Henry SM, Raasch CC, Hitt JR, Bunn JY. Individuals with non-specific low back pain use a trunk stiffening strategy to maintain upright posture. J Electromyogr Kinesiol. 2012;22(1):13-20.

21. Mann L, Kleinpaul JF, Pereira Moro AR, Mota CB, Carpes FP. Effect of low back pain on postural stability in younger women: influence of visual deprivation. J Bodyw Mov Ther. 2010;14(4):361-366.

22. Ruhe A, Fejer R, Walker B. Is there a relationship between pain intensity and postural sway in patients with non-specific low back pain? BMC Musculoskelet Disord. 2011;12:162.

23. Lihavainen K, Sipilä S, Rantanen T, Sihvonen S, Sulkava R, Hartikainen S. Contribution of musculoskeletal pain to postural balance in community-dwelling people aged 75 years and older. J Gerontol A Biol Sci Med Sci. 2010;65(9):990-996. 


\section{Publish your work in this journal}

Clinical Interventions in Aging is an international, peer-reviewed journal focusing on evidence-based reports on the value or lack thereof of treatments intended to prevent or delay the onset of maladaptive correlates of aging in human beings. This journal is indexed on PubMed Central, MedLine,

CAS, Scopus and the Elsevier Bibliographic databases. The manuscript management system is completely online and includes a very quick and fair peer-review system, which is all easy to use. Visit http://www.dovepress. com/testimonials.php to read real quotes from published authors. 